\title{
FOTOGRAFI POTRET RELAWAN RUMAH HARAPAN VALENCIA CARE FOUNDATION
}

\section{Rezha Destiadi}

\author{
Program Studi Desain Komunikasi Visual \\ Fakultas Bahasa dan Seni Universitas Indraprasta PGRI \\ Jl. Nangka 58 Tanjung Barat, Jakarta Selatan, Indonesia \\ rezhadestiadi@gmail.com
}

\begin{abstract}
Abstrak
Kerelawanan merupakan bagian dari modal dasar dalam mencapai perubahan. Salah satunya dalah sukarelawan yang bergerak aktif di Rumah Harapan Valencia Care Foundation. Mereka berdiri, dan juga hidup berdampingan dengan pasien-pasien yang berjuang untuk sembuh namun belum memiliki kesempatan waktu untuk berobat di Rumah Sakit. Kehadiran para relawan ini patut diapresiasi agar perubahan ke arah lebih baik segera tercapai. Berbagai bentuk apresiasi bisa diterapkan. Salah satunya adalah menghadirkan profil setiap relawan dalam bentuk fotografi potret dengan pendekatan foto cerita. Kehadiran fotografi potret berupaya merekam identitas relawan dalam bentuk visual yang di dalamnya menampilkan raut wajah, karakteristik, arah pandang mata, gerak tubuh, hingga ekspresi. Terdapat 9 profil relawan yang dihadirkan dalam bentuk foto potret dengan menggunakan teknik pencahayaan Horst.
\end{abstract}

Kata kunci : Relawan, fotografi, Potret, Horst.

\begin{abstract}
Volunteering is part of the basic capital in achieving change. One of them is an active volunteer at the Rumah Harapan Valencia Care Foundation. They stand, and also live side by side with patients who are struggling to recover but have not had time to seek treatment at the hospital. The presence of these volunteers should be appreciated for a change to be better soon achieved. Various forms of appreciation can be applied. One of them is to present the profile of each volunteer in the form of portrait photography with photo story approach. The presence of portrait photography attempts to record the identity of volunteers in a visual form in which it displays facial features, characteristics, eye-to-eye, gestures, and expressions. There are 9 profiles of volunteers who have been presented in the form of portrait photographs.
\end{abstract}

Keywords: Volunterism, Photography, Portrait, Horst 


\section{PENDAHULUAN}

Berdasarkan UU Nomor 4 Tahun 1992 tentang perumahan dan permukiman, rumah adalah bangunan yang berfungsi sebagai tempat tinggal atau hunian dan sarana pembinaan keluarga. Rumah bagian dari tempat manusia bisa merasakan kasih sayang, saling berbagi, bercengkrama dengan keluarga. Sekedar bercerita keseharian bahkan bertengkar dengan kakak atau adik.

Rumah tempat dimana seseorang pulang saat sudah selesai beraktifitas di kantor, kampus, atau sekolah, dan tempat dimana individu bisa menjadi diri sendiri. Rumah juga menjadi tempat berlindung dari panas dan hujan. Saat sehat atau sakit ringan yang tidak perlu menginap di rumah sakit. Rumah memang sangat dibutuhkan bagi kita semua.

Bicara mengenai rumah, rumah tak hanya bisa ditinggali oleh anggota keluarga, ada rumah yang dikhususkan untuk menampung orang-orang yang membutuhkan tempat tinggal sementara yang biasa dikenal dengan nama rumah singgah. Konferensi Nasional II dalam pada bulan Juli 1996 yang dikutip oleh Fathoni (2009) mendefinisikan rumah singgah sebagai tempat pemusatan sementara yang bersifat non formal. Keberadaannya juga sudah bisa ditemukan di lingkungan sekitar. Proses pendiriannya ada yang dilakukan oleh pemerintah, Lembaga Swadaya Masyarakat, bahkan personal. Seperti halnya Rumah Harapan Valencia Care Foundation. Rumah Harapan Valencia ini didirikan oleh Valencia Mieke Randa bersama teman-temannya.

Rumah Harapan Valencia Care Foundation didirikan secara khusus untuk menampung orang sakit terutama anak-anak Leukeima, yang datang dari daerah dan belum dapat tertampung di Rumah Sakit karena kapasitas kamar yang terbatas. Keberadaan Rumah
Harapan tersebut bisa sedikit membantu orang tuanya yang memiliki keterbatasan finansial mempunyai harapan kesembuhan untuk anaknya.

Rumah Harapan Valencia Care Foundation merupakan impian dari sang founder, Valencia sejak tahun 2012. Sang founder sudah sering berkunjung ke rumah sakit RSCM untuk mengunjungi anak-anak yang sakit, walau hanya sekedar membacakan buku cerita, bercerita untuk memotivasi dan mengajak bermain bersama. Setidaknya hal ini sedikit meringankan penderitaan anakanak yang sedang berjuang melawan penyakitnya.

Alasannya melakukan kegiatan tersebut dikarenakan intensitas aktifitas yang dilakukan ditambah melihat keadaan orang tua yang duduk pasrah di selasar selasar rumah sakit, terlihat raut muka yang lelah dan sedih, tanpa tahu harus berbuat apa, karena mereka datang dari daerah dan hanya membawa surat rujukan dari Puskesmas. Berbekal pengetahuan dan dana yang terbatas, mereka berangkat ke Jakarta dengan harapan setibanya disana mereka langsung bisa dirawat di Rumah Sakit. Namun kondisi di lapangan tidak sesuai harapan. Bahkan kondisi ekonomi mereka pun sampai menipis karena proses pengobatan yang memakan waktu lama dan biaya yang tidak sedikit jumlahnya. Menurut Departemen Sosial, rumah singgah adalah perantara penghuni dengan pihak-pihak yang akan membantu mereka. Pihak-pihak yang membantu disini adalah yayasan dan para relawan.

$$
\text { Termasuk Rumah Harapan }
$$

Valencia Care Foundation yang di dalamnya terdapat relawan yang bekerja secara sukarela mendampingi anak-anak yang sakit di Rumah Harapan Valencia Care Foundation Care Foundation. Mereka hadir untuk mendampingi anakanak yang sedang sakit, merawatnya seperti anak sendiri, hingga memberikan 
program-program menarik terkait menyembuhkan anak-anak secara psikologis.

Keberadaan Rumah Harapan Valencia Care Foundation beserta para relawannya (volunteer) merupakan bagian dari kota yang tidak bisa diacuhkan begitu saja. Kota menurut Piliang (2010) merupakan ruang yang di dalamnya berlangsung interaksi manusia secara sosial dan komunikasi manusia dengan berbagai medianya. Sebagai salah satu rumah singgah, Rumah Harpan Valencia Care Foundation tengah menjalankan fungsi kota sebagai fungsi utilitas (Piliang, 2010:228). Fungsi utilitas dari Rumah Harapan yang menggunakan konsep rumah hunian di tengah kota dengan menambahkan nilai lebih di dalamnya.

Nilai lebih dari aktifitas mulia para relawan di Rumah Harapan Valencia Care Foundation ini sangatlah mendasar bagi individu sebagai manusia yang saling berkomunikasi satu sama lain. Ditinjau dari segi teoritis, komunikasi dimaknai sebagai jalur yang menghubungkan diri dengan dunia, sarana menampilkan kesan, mengekspresikan diri dan juga mempengaruhi orang lain (Ruben dan Lea, 2013:17).

Para relawan bergerak dan hidup secara berdampingan dengan anak-anak yang sedang dalam proses perjuangan untuk sembuh. Mereka berupaya semaksimal mungkin untuk mempengaruhi para pasien dalam berbagai aspek. Sebut saja aspek psikis, dimana keberadaan mereka (baca: relawan) menjadi semangat bagi para anak-anak agar tetap optimis mencapai kesembuhan. Aspek lingkungan, para relawan berjuang menciptakan kondisi dan situasi yang nyaman, sehingga anak-anak mendapatkan kehidupan yang layak. Aspek jasmani, dimana anak-anak tersebut selalu mendapat perhatian dari apa yang dikonsumsi. Keseluruhan aspek tersebut merupakan bagian dari bentuk kepedulian para relawan yang hidup secara berdampingan dengan anak-anak yang tidak dalam kondisi sehat. Hal inilah yang menjadi alasan tim melakukan pengabdian kepada masyarakat dengan cara mengangkat profil masing-masing relawan ke dalam bentuk media visual foto potret.

\section{PEMBAHASAN}

Fitrah seorang manusia adalah terlahir baik. Namun, dalam perjalanan hidup setiap individu tentu akan mengalami perbedaan sifat. Seperti halnya alam semesta yang selalu menciptakan dua hal yang berbedaberhubungan. Ada laki - perempuan, siang - malam, hujan - panas, juga baik dan buruk.

Dalam hubungannya dengan konsep di atas, ada orang-orang yang lebih mementingkan kehidupan diri sendiri. Namun, ada pula orang-orang yang tingkat kepeduliannya sangat tinggi. Mereka adalah para relawan. Kerelawanan atau volunterism adalah aktivitas menolong yang lebih bersifat proaktif daripada reaktif, dan menuntut waktu serta usaha yang lebih banyak (Abidah, 2012). Mereka bekerja dalam gerakan kemanusiaan untuk kepentingan masyarakat yang bekerja sukarela tanpa mengharapkan keuntungan. Mereka berdiri di atas kekuatan moral, dan semangat tolong-menolong.

Relawan dan Kerelawanan telah menjadi wacana yang sangat kuat. Keduanya menjadi sebuah gerakan sosial sekaligus menjadi modal sosial yang dahsyat untuk menciptakan perubahan (Veni dalam Icha, 2010). Berbagai motif yang mendasari para relawan bekerja menurut Sears (2009) di antaranya:

1. Relawan menekankan pada nilai personal seperti kasih sayang terhadap sesama. 
2. Fungsi dari tindakan sukarela adalah untuk mendapatkan pemahaman yang lebih mendalam untuk mempelajari suatu kejadian sosia, mengeksplorasi kekuatan personal, mengembangkan keterampilan baru, dan belajar bekerja sama dengan berbagai macam orang.

3. Merefleksikan keinginan untuk berteman dan mendapatkan penerimaan sosial.

4. Mengeksplorasi posisi karir, membangun kontak potensial bernilai sosial.

5. Proteksi diri. Merasa tidak kesepian, mereduksi perasaan bersalah.

6. Membantu orang merasa dibutuhkan atau menjadi penting

Salah satu tempat yang bisa dijumpai keberadaan relawan, adalah rumah singgah. Rumah Harapan Valencia Care Foundation, salah satunya. Rumah Harapan Valencia Care Foundation merupakan tempat para relawan bernaung dan memberikan rasa kasih sayang dan kepeduliannya kepada anak-anak yang sedang sakit dan berjuang untuk sembuh. Mereka dengan sukarela hidup berdampingan dengan para pasien yang sedang berada di rumah singgah tersebut.

\section{Potret Relawan}

Secara etimologis, fotografi potret merupakan hasil representasi perekaman/ pengabadian likeness (kemiripan) jati diri figur manusia dalam bentuk dwimatra (gambar) (Soedjono, 2010:111). Sebagai sebuah genre, fotografi potret sebelumnya telah hadir dan terwadahi dalam bentuk seni lukis, patung, dan relief-relief (Irwandi dan Fajar, 2012:1). Hal ini juga menjadi acuan dasar manusia yang senang dan ingin apabila dirinya dihadirkan dalam bentuk visual. Visual berupa foto potret seperti sebuah petunjuk yang mengarahkan interpretasi terhadap subyek tertentu. Termasuk ketika peneliti merekam profil-profil para relawan yang berada di Rumah Harapan Valencia Care Foundation.

Perancangan foto potret para relawan Rumah Harapan Valencia Care Foundation menggunakan pendekatan foto cerita. Alasan pendekatan tersebut merujuk pada apa yang dikatakan oleh Wijaya (2016:14), bahwa foto cerita merupakan foto yang mampu menyampaikan pesan yang kuat, membangkitkan semangat, menghadirkan perasan haru, menghibur, hingga memancing perdebatan.

Jenis foto cerita yang akan dirancang adalah series. Series yang dikutip dalam Wijaya (2016) adalah satu set rangkaian foto seragam yang didesain untuk mengilustrasikan satu poin perbandingan. Satu set yang berisi 9 foto potret relawan Rumah Harapan Valencia Care Foundation.

Keseluruhan konsep perekaman potret para relawan adalah hitam - putih (Black \& White). Fotografi hitam putih dipilih karena kekuatannya yang terletak pada gradasi warnanya. Fotografi hitam putih juga mengandalkan bentuk dan garis, karena kombinasi bentuk, garis, dan gradasi warna hitam putih akan membangun irama dalam sebuah karya hitam putih. Diharapkan karya fotografi potret dengan format hitam putih dan didukung dengan teknik pencahayaan khusus akan membuat pesan yang disampaikan secara visual lebih kuat.

Dalam proses pelaksanaan pendokumentasiannya, peneliti menggunakan teknik pencahayaan khusus yaitu Horst Lighting. Pengertian Teknik Horst yang dimaknai dalam channel youtube Kelas Pagi Jakarta (2016) merupakan upaya fotografer yang bernama sama (P. Horst) dalam mewujudkan ciri khas pencahayaan. Karakteristik utama dari Horst ini adalah kontras atau perbedaan gelap dengan terang yang sangat pekat. 
Untuk mencapai karakteristik dari teknik tersebut di atas, fotografer menggunakan pencahayaan buatan berupa 2 buah lampu continuous (Red Heat) 800 watt. Sifat dari lampu tersebut memancarkan warna yang kekuningan dan suhu yang sangat panas. Untuk latar belakangnya sendiri (backdrop), menggunakan latar belakang polos berupa kain putih berukuran 3 × $6 \mathrm{~m}$ dengan tambahan perlengkapan berupa standing background.

Teknik Horst Lighting digunakan sebagai upaya dalam mempresentasikan setiap profil agar lebih fokus. Fokus kepada raut muka, arah pandang mata, gesture, dan juga ekspresi setiap relawan. Kontrasnya sebagai pemberi makna akan kondisi relawan di dalam interaksi sosial. Relawan hadir di tengah interaksi, namun butuh lebih banyak apresiasi.

Selama proses pengabdian kepada masyarakat berlangsung, peneliti telah mengumpulkan 9 relawan yang difoto satu per satu. Demi menunjang pemunculan karakteristik tiap relawan, tim abdimas dan khususnya fotografer melakukan dua metode. Metode pertama adalah wawancara singkat dan padat kepada beberapa relawan untuk menghasilkan keyword yang kemudian bisa diterjemahkan oleh fotografer menjadi sebuah konsep atau layout pemotretan. Metode yang kedua adalah melalui observasi atau pengamatan. Proses pengamatan ini dilakukan saat wawancara berlangsung dan juga dilakukan saat terjalin obrolan singkat kepada subyek relawan yang akan difoto. Metode ini merupakan metode yang paling tepat mengingat sebagian wawancara yang tidak bisa dilakukan karena waktu yang terbatas.

Dalam hal ini, posisi fotografer mempunyai peran ganda. Satu hal Ia menjadi seorang juru foto. Namun sebelumnya ia menjadi satu hal lainnya yakni sebagai seorang stylist, seseorang dengan kemampuan mengarahkan gaya yang tepat untuk setiap relawan. Berbagai peran tersebut dikategorikan oleh Setyadi dalam Sumayku (2017) sebagai The Art of Seeing. Ia melanjutkan bahwa The Art of Seeing adalah kecakapan seseorang melihat obyek yang menonjol untuk direkam secara visual melalui alat kamera. Poin menonjol diterjemahkan seluas-luasnya, mulai dari sudut pandang, teknis, karakteristik, atau arah pandang mata, hingga gesturenya.

Dalam pelaksanaannya, tim mendokumentasikan sembilan orang relawan, terdiri dari 2 orang laki-laki, 7 orang perempuan.

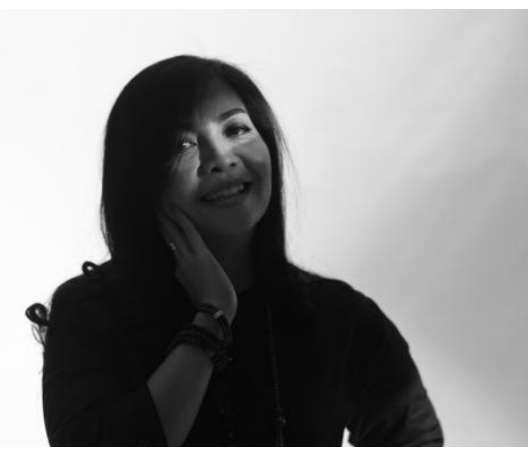

Gambar 1.1

Valencia Mieke Randa, 39 Tahun

Founder Rumah Harapan Valencia Care Foundation (sumber: rezhaban, 2017).

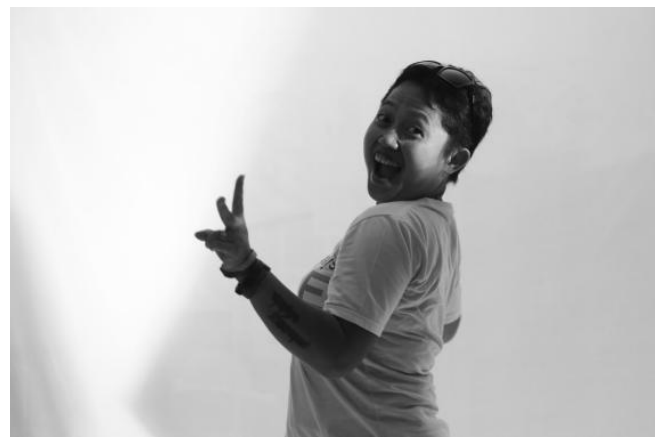

Gambar 1.2

Relawan: Lia, 34 Tahun (sumber: rezhaban, 2017). 


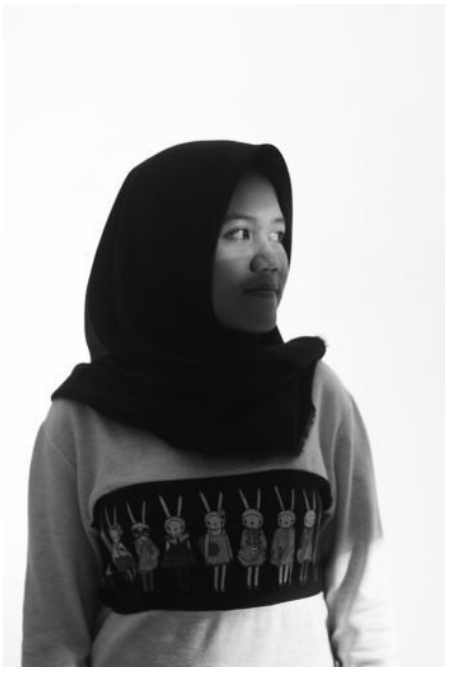

Gambar 1.3

Relawan: Dewi Permatahati, 19 Tahun (sumber: rezhaban, 2017).

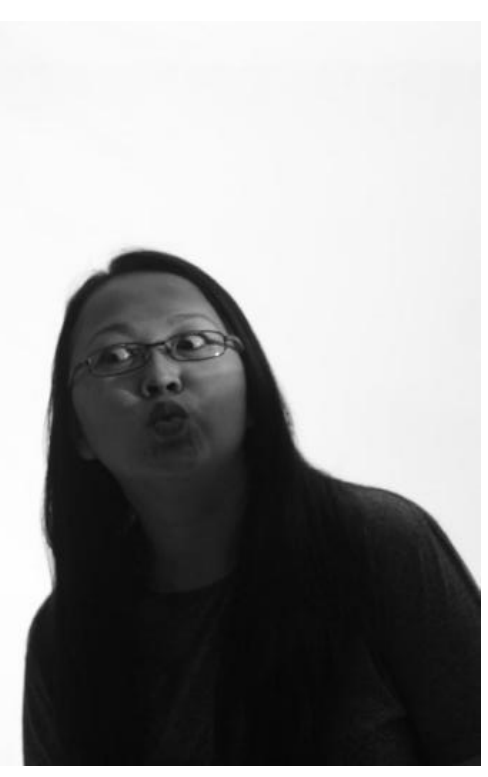

Gambar 1.6

Relawan: Dwi Wulan Juni Tara, 24 Tahun (sumber: rezhaban, 2017).

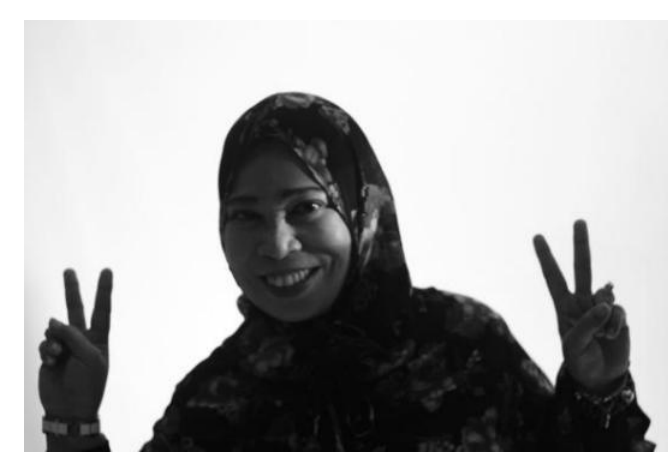

Gambar 1.4

Relawan: Aini, 43 Tahun (sumber: rezhaban, 2017).

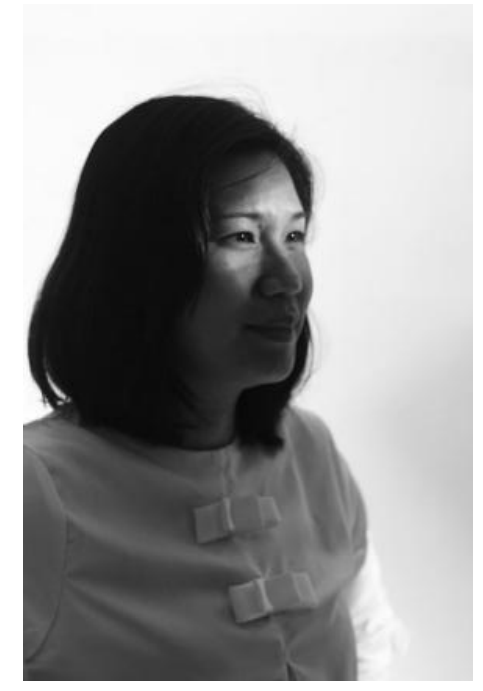

Gambar 1.5

Relawan: Jessica Cahyan, 37 Tahun (sumber: rezhaban, 2017).

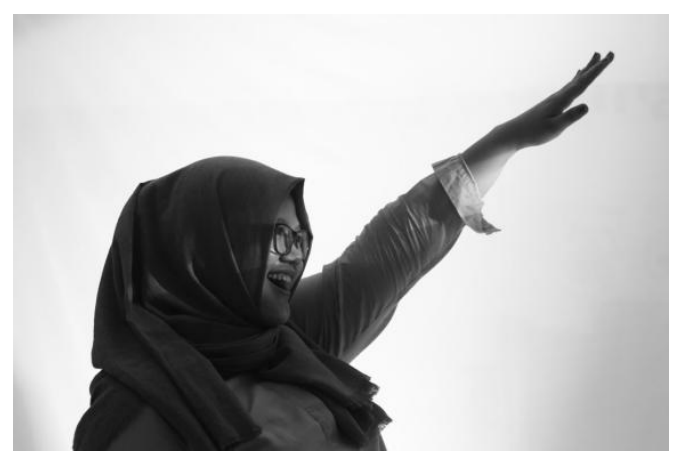

Gambar 1.7

Relawan: Dessy, 32 Tahun (sumber: rezhaban, 2017). 


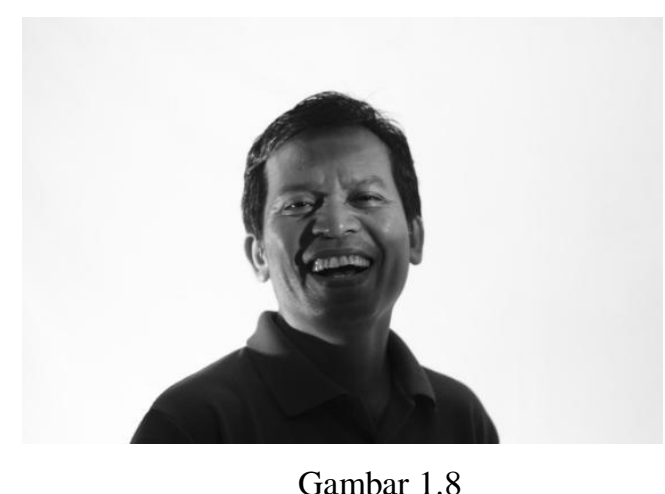

Relawan: Patric Y. M, 51 Tahun (sumber: rezhaban, 2017).

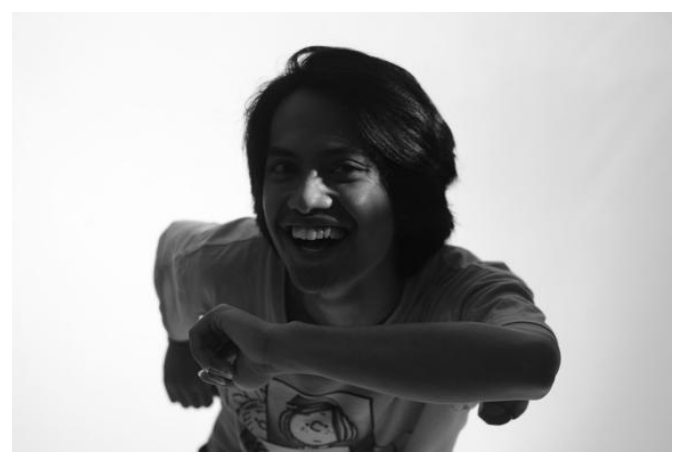

Gambar 1.9

Relawan: Rindo, 26 Tahun (sumber: rezhaban, 2017).

Kehadiran foto potret para relawan diimplementasikan dengan tujuan menghasilkan nilai personal dan juga sosial. Nilai tersebut berkaitan erat seperti yang dahulu pernah dikatakan oleh Barbara \& John Upton (1994) bahwa "People wanted portraits". Nilai personal merujuk pada kecenderungan manusia yang senang apabila dirinya terabadikan dalam bentuk potret. Nilai sosial memanfaatkan medium fotografi sebagai petunjuk visual dan apresiasi dari kehadiran para relawan di lingkungan Rumah Harapan Valencia Care Foundation, Jakarta.

\section{PENUTUP}

Kegiatan pengabdian kepada masyarakat dalam bentuk visualisasi foto potret para relawan bertujuan menghasilkan nilai personal dan nilai sosial. Nilai tersebut berkaitan erat seperti yang dahulu pernah dikatakan oleh Barbara \& John Upton (1981) bahwa "People wanted portraits". Nilai personal merujuk pada kecenderungan manusia yang senang apabila dirinya terabadikan dalam bentuk potret. Nilai sosial memanfaatkan medium fotografi sebagai petunjuk visual dan apresiasi dari kehadiran para relawan di lingkungan Rumah Harapan Valencia Care Foundation, Jakarta.

\section{DAFTAR PUSTAKA}

Abidah, M.. (2012). Kebermaknaan Hidup Seorang Relawan. Surabaya: Program Studi Psikologi IAIN Sunan Ampel.

Irwandi \& Apriyanto, M. F. (2012). Membaca Fotografi Potret (Teori, Wacana, dan Praktik). Yogyakarta: Gama Media.

Kurnila, I. (2013). Perilaku Prososial Relawan Yayasan Ummi Fadhilah Surabaya.

Surabaya: Program Studi Psikologi IAIN Sunan Ampel.

London, B. and Upton, J. (1994). Photography, New York: Harper Collins College Publisher,

Piliang, Y.A. (2011). Dunia yang Dilipat: Tamasya Melampaui Batasbatas Kebudayaan. Bandung: Matahari.

Ruben, B.D. \& Stewart, L.P. (2013). Komunikasi dan Perilaku 
Manusia. Jakarta: Rajawali Pers.

Soedjono, S. (2005). Pot-Pourri Fotografi. Jakarta: Penerbit Universitas Trisakti.

Sumayku, R. (2016). Pada Suatu Foto. Bandung: Kaifa Publishing.

Taylor, S. E., Letitia A. P., \& David O. S. (2009). Psikologi Sosial Edisi kedua belas. Jakarta: Kencana.
Undang-undang Nomor 4,Tahun 1992 tentang Perumahan dan Permukiman.

Wijaya, T. (2016). Photo Story Handbook (Panduan Membuat Foto Cerita). Jakarta: Gramedia Pustaka Utama.

Website:

http://digilib.uin-suka.ac.id, diakses 8 September 2017.

www.youtube.com/Kelas Pagi Jakarta. 